\title{
Glycerol-dimethacrylate as alternative hydrophilic monomer for HEMA replacement in simplified adhesives
}

\author{
V.G. Araújo-Neto ${ }^{a}$, C.F.A. Nobre ${ }^{a}$, D.M. De Paula ${ }^{b}$, L.C. Souza ${ }^{b, c}$, J.C. Silva ${ }^{b}$, M.M. Moreira ${ }^{b}$, \\ P.R.B. Picanço ${ }^{c}$, V.P. Feitosa ${ }^{\text {b,c,* }}$ \\ a Catholic University Center of Quixadá, Centro Universitário Católica de Quixadá, Quixadá, Brazil \\ ${ }^{\mathrm{b}}$ Post-graduation Program in Dentistry, Federal University of Ceará, Fortaleza, Brazil \\ ${ }^{\mathrm{c}}$ Paulo Picanço School of Dentistry, Fortaleza, Brazil
}

\section{A R T I C L E I N F O}

\section{Keywords:}

Dentin

Polymerization

Biomaterials

\begin{abstract}
A B S T R A C T
Objectives: Hydroxyethyl-methacrylate (HEMA) is still widely used in simplified adhesives. Indeed, several shortcomings occur with this monomer, such as water uptake and formation of linear polymers. This study aimed to compare the effects of HEMA replacement by glycerol-dimethacrylate (GDMA) on selected physicochemical properties and bonding performance of simplified model adhesives.

Materials and Methods: Experimental simplified etch-and-rinse and self-etch adhesives were formulated containing $20 \mathrm{wt} \%$ HEMA or GDMA. Three-point bending test was used to obtain the elastic modulus of bar-shaped specimens, and water sorption and solubility were attained by ISO-4049 (ISO, 2009) method. Degree of conversion was surveyed by Micro-Raman spectroscopy, and microtensile bond strength was tested after $24 \mathrm{~h}$ or 6 months simulated pulpal pressure aging. Statistical analysis was realized with two-way ANOVA and Tukey's test $(\mathrm{p}<0.05)$.

Results: GDMA promoted higher elastic modulus to the self-etch adhesive, and GDMA-containing etch-and-rinse adhesive achieved overall lower water sorption and solubility. The degree of conversion was statistically higher for GDMA adhesives than for HEMA etch-and-rinse one. All bond strengths dropped significantly after aging, except that of GDMA self-etch adhesive. The nanoleakage was higher and gaps were found in the interface of HEMA-containing adhesives, which were less present in GDMA equivalents.

Conclusions: GDMA is a feasible hydrophilic dimethacrylate monomer to replace HEMA in simplified adhesives, thereby providing better polymerization, mechanical properties and dentin adhesion as well as lower water uptake and solubility.
\end{abstract}

\section{Introduction}

Upon the composition of simplified dental adhesives, hydrophilic monomers able to aid the infiltration of hydrophobic adhesive blend into partially-demineralized wet dentin are widely encountered (Van Meerbeek et al., 2011). Hydroxyethyl-methacrylate (HEMA) is the hydrophilic monomer most used in commercial adhesives, due to its low molecular weight and "solvent" ability thereby reducing the viscosity and ameliorating the miscibility of water and hydrophobic monomers (Van Landuyt et al., 2008). Nevertheless, HEMA (Fig. 1A) possesses only one polymerizable functionality (it is a mono-methacrylate), promoting the formation of only linear polymer chains. Often, such monomer is found in relatively high concentrations that might result in higher polymer degradation, low degree of cross-linking and HEMA leaching to the pulp, which may cause cytotoxicity (Gallorini et al.,
2014; Barbosa et al., 2015).

To overcome negative effects of HEMA, Zanchi et al. (2013) proposed the use of high-molecular weight surfactant monomers. These monomers are relatively hydrophilic long carbon-chain dimethacrylates that were included in small amounts of three-step etch-and-rinse and self-etch adhesives (Zanchi et al., 2013; Münchow et al., 2014) in order to diminish hydrolytic degradation and prevent phase separation. The durability of composite restorations is directly related to the mechanical properties, water sorption and solubility of adhesive resins. Although HEMA is widely employed in the current simplified adhesives, the presence of such monomer is also associated with rapid degradation processes of resin-dentin interface (Van Landuyt et al., 2007), promoting the water seepage from dentinal tubules and formation of water droplets within adhesive layer (Van Landuyt et al., 2008).

Glycerol dimethacrylate (GDMA) is a hydroxyl-containing

\footnotetext{
* Correspondence to: Lab PPGO-UFC, Dental School, Federal University of Ceará, Rua Monsenhor Furtado S/N, Fortaleza 60430-350, CE, Brazil.

E-mail addresses: victorpfeitosa@hotmail.com, victor.feitosa@facpp.edu.br (V.P. Feitosa).
} 
A<smiles>C=C(C)C(=O)OCCO</smiles>

Hydroxy-ethyl-methacrylate (HEMA)<smiles>C=C(C)C(=O)OCC(O)COC(=O)C(=C)C</smiles>

Glycerol-dimethacrylate (GDMA)

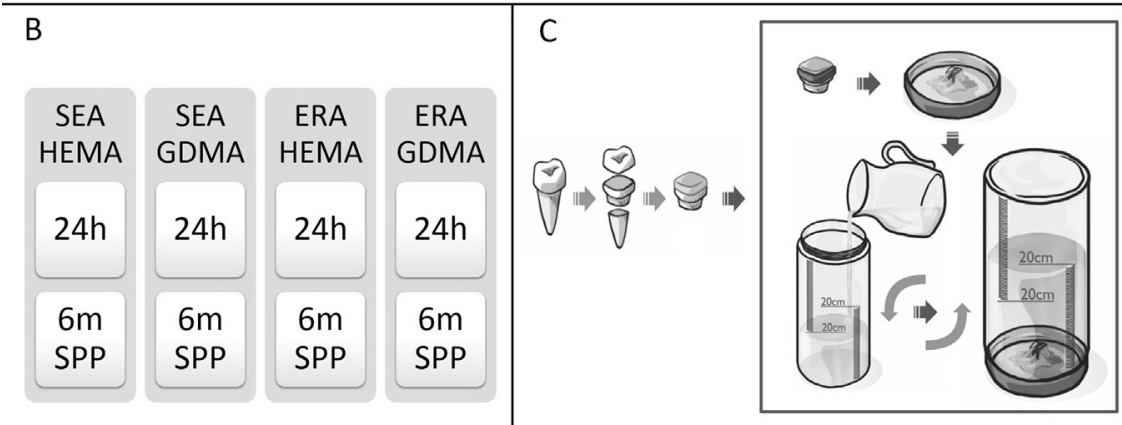

Fig. 1. Experimental design of the study. A- Chemical structures of hydroxyethyl-methacrylate (HEMA, left) and glycerol-dimethacrylate (GDMA, right). B- Schematic division of groups tested in microtensile bond strength evaluation, where ERA (etchand-rinse adhesive) and SEA (self-etch adhesive) were experimentally formulated. 6-SPP means 6 months of simulated pulpal pressure. C- Schematic drawing of specimens' preparation under simulated pulpal pressure regimen to induce aging of bonded teeth under $20 \mathrm{~cm} \mathrm{H}_{2} \mathrm{O}$ hydrostatic pressure. hydrophilic functional monomer (Fig. 1A) with low molecular weight, which may replace HEMA due to its hydrophilic characteristics, but generating crosslinked polymers upon polymerization. Furthermore, GDMA might improve mechanical properties and afford adhesives with higher hydrolytic resistance, thereby reducing degradation and leaching of monomers with consequent lower cytotoxicity (Becher et al., 2006). Nevertheless, to our knowledge, no reports regarding the replacement of HEMA by GDMA have been published so far.

Therefore, the aim of this in vitro investigation was to assess the physicochemical and adhesion properties of simplified experimental self-etch and etch-and-rinse adhesives containing standardized concentration of HEMA or GDMA. The null hypotheses tested were (1) GDMA does not improve physicochemical properties of simplified adhesives; and (2) GDMA does not ameliorate dentin bonding of experimental adhesives tested.

\section{Materials and methods}

\subsection{Formulation of experimental adhesives}

A self-etch adhesive (SEA) resin was prepared by mixing $20 \mathrm{wt} \%$ urethane-dimethacrylate (UDMA), $20 \mathrm{wt} \%$ hydroxyethyl-methacrylate (HEMA) or glycerol dimethacrylate (GDMA), $15 \mathrm{wt} \%$ hydroxyethylmethacrylate-phosphate (HEMA-P), $15 \mathrm{wt} \%$ deionized water, $30 \mathrm{wt} \%$ absolute ethanol and $1.5 \mathrm{wt} \%$ photoinitiation system. The photosensitive molecule used was camphoroquinone (CQ, $0.5 \mathrm{wt} \%$ ). The ethyl 4- dimethylaminebenzoate (EDAB, $1 \mathrm{wt} \%$ ). An etch-and-rinse adhesive (ERA) resin was prepared by mixing $20 \mathrm{wt} \%$ UDMA, $10 \mathrm{wt} \%$ bisphenol-A-glycidyl-dimethacrylate (BisGMA), $20 \mathrm{wt} \%$ HEMA or GDMA, $10 \mathrm{wt} \%$ deionized water, $40 \mathrm{wt} \%$ absolute ethanol and $1.5 \mathrm{wt} \%$ photoinitiation system ( $0.5 \mathrm{wt} \%$ CQ and $1 \mathrm{wt} \%$ EDAB).

\subsection{Water sorption and solubility test}

Water sorption and solubility tests were based on the 4049 ISO standard, except for specimen's dimensions $(8.0 \mathrm{~mm}$ diameter $\mathrm{x} 1.0 \mathrm{~mm}$ thickness). Specimens were created with standardized silicone molds and were individually light-cured by the LED unit DB85 (Dabi Atlante, Ribeirão Preto, Brazil) with $1100 \mathrm{~mW} / \mathrm{cm}^{2}$ irradiance $40 \mathrm{~s}$. After $24 \mathrm{~h}$, the specimens were placed in a desiccator device containing silica gel and stored at $37^{\circ} \mathrm{C}$ under vacuum. The specimens were repeatedly weighed on an analytical balance $\pm 0,0001 \mathrm{~g}$ (Metter-Toledo AG285, São Paulo, Brazil) every $24 \mathrm{~h}$, until a constant mass in which variation was less than $0.2 \mathrm{mg}$ within a $24 \mathrm{~h}$ period $(\mathrm{m} 1)$ was obtained (Chimeli et al., 2014). The thickness and diameter of the specimens were measured at three different points to the nearest $0.01 \mathrm{~mm}$ using a digital caliper, and these measurements were used to calculate the volume (V) of each specimen (in $\mathrm{mm}^{3}$ ). Specimens were then individually placed in test tubes (Eppendorf vials) containing $1.5 \mathrm{~mL}$ of distilled water $(\mathrm{pH}$ 7.2) at $37^{\circ} \mathrm{C}$ for 7 days. Afterwards, the tubes were removed from the incubator and left to equilibrate at room temperature for $30 \mathrm{~min}$. The specimens were gently wiped with a soft absorbent paper, weighed in an analytical balance (m2). Further, the specimens were dried inside a desiccator containing fresh silica gel and weighed daily until a constant mass (m3) was obtained (as previously described). The initial mass determined after the first desiccation process (m1) was used to calculate the mass change after each fixed-time interval of the 7 days of storage. Changes in mass were plotted to obtain the water sorption and solubility. The water sorption (Wsp) and solubility (Wsl) over 7 days of water storage were calculated $\left(\mu \mathrm{g} / \mathrm{mm}^{3}\right)$ by means of the following formulae [10]:

$W s p=\frac{m 2-m 3}{V}$

$W s l=\frac{m 1-m 3}{V}$

Where, $\mathrm{m} 1$ refers to the initial dry constant mass (mg) prior to immersion in water; $\mathrm{m} 2$ is ascribed to the mass (mg) after water immersion at various time periods; $\mathrm{m} 3$ is the mass $(\mathrm{mg})$ after final drying the specimens, and V refers to the specimen volume $\left(\mathrm{mm}^{3}\right.$ ) (Argolo et al., 2015). Data were analyzed by two-way ANOVA and Tukey's post-hoc test $(\mathrm{p}<0.05)$.

\subsection{Flexural modulus}

Bar-shaped specimens $(n=8)$ of each experimental adhesive were created using silicone molds $(0.5 \mathrm{~mm}$ thickness, $7 \mathrm{~mm}$ length and $2 \mathrm{~mm}$ width). The assessment was realized following a protocol similar to that of Loguercio et al. (2009). The resins were poured into the molds without solvent evaporation and gently air-blasted for $20 \mathrm{~s}$. A polyester strip covered the resins and the light-activation was undertaken using DB85 LED curing unit (Dabi Atlante) with $1100 \mathrm{~mW} / \mathrm{cm}^{2}$ irradiance was realized for $40 \mathrm{~s}$ with the light tip in contact with strip (on the top of the specimen). The light tip diameter was $10 \mathrm{~mm}$; therefore, it covered the entire specimen allowing a single light-activation for each specimen. Specimens were carefully removed from the molds and stored in a dark environment with 100\% relative humidity for $24 \mathrm{~h}$. Specimens were tested on three-point bending set-up $(5 \mathrm{~mm}$ span 
between supports) in a universal testing machine (Instron 4484; Instron Inc., Canton, USA), with a $500 \mathrm{~N}$ load cell at $0.5 \mathrm{~mm} / \mathrm{min}$ crosshead speed. Load-displacement curves were converted to stress-strain curves. Width and thickness of the specimens were measured and the elastic modulus was calculated at $10 \%$ strain. The exact cross-sectional area of each tested specimen was measured before testing using a digital caliper. The data were transformed to MPa. The results were statistically analyzed using two-way ANOVA and Tukey's test ( $\mathrm{p}<0.05)$.

\subsection{Degree of conversion (DC)}

Micro-Raman spectroscopy analysis was used to assess the degree of conversion of adhesives $10 \mathrm{~min}$ after light-curing. The micro-Raman spectrophotometer (Xplora, Horiba JobinYvon, Paris, France) was firstly calibrated using a silicon standard sample supplied by the manufacturer. HeNe laser with $3.2 \mathrm{~mW}$ power and $532 \mathrm{~nm}$ wavelength was employed with $1.5 \mu \mathrm{m}$ spatial resolution, $2.5 \mathrm{~cm}^{-1}$ spectral resolution associated with $10 \times$ magnification lens (Olympus, London, UK). The degree of conversion was calculated based in a previous investigation [13] by means of the formula:

$\mathrm{DC} \%=\left(1-\frac{\mathrm{R}_{\text {cured }}}{\mathrm{R}_{\text {uncured }}}\right) \times 100$

Where $\mathrm{R}$ is the ratio between the heights of $1639 \mathrm{~cm}^{-1}$ and $1609 \mathrm{~cm}^{-1}$ peaks of uncured and light-cured material. Three readings were undertaken on the top surface of each specimen (Miletic and Santini, 2012). The results were statistically analyzed using two-way ANOVA and Tukey's test $(\mathrm{p}<0.05)$.

\subsection{Microtensile bond strength ( $\mu T B S$ )}

Extracted human third molars were used after approval of the Institutional Ethics Committee (protocol 127/2011) and stored in 0.5\% thymol/water solution at $4{ }^{\circ} \mathrm{C}$ for no longer than four months. Deep dentin specimens with remaining dentin thickness of approximately $0.9 \mathrm{~mm}$ [14] were obtained by removing the roots $2 \mathrm{~mm}$ beneath cemento-enamel junction (CEJ) and the occlusal crown $2 \mathrm{~mm}$ above CEJ using a slow-speed water-cooled diamond saw (Isomet 1000; Buehler, Lake Bluff, IL, USA). The pulpal tissue was removed with small tweezers without scratching the pre-dentin surface along the walls of the pulpal chamber. The dentin surface of each specimen was wet-abraded with a \#600 SiC paper for $60 \mathrm{~s}$ to create a standard smear-layer. The specimens were thoroughly rinsed using deionised water $(5 \mathrm{~s})$ and immediately bonded with the tested experimental adhesives. They were actively applied for $30 \mathrm{~s}$, gently air-dried and light-cured for $40 \mathrm{~s}$ using the DB85 unit $\left(1100 \mathrm{~mW} / \mathrm{cm}^{2}\right)$. For etch-and-rinse adhesives, this was conducted after $15 \mathrm{~s} 35 \%$ phosphoric acid etching (Condac, FGM, Joinville, Brazil). TPH Spectrum (Dentsply Caulk, USA) composite was used for build-ups.

Subsequent to the restorative procedures, the specimens of each group were divided into two subgroups based on the aging protocol (Fig. 1B):

1) Control: immersion in deionized water for $24 \mathrm{~h}\left(37^{\circ} \mathrm{C}\right)$ and subsequently sectioned into sticks;

2) Simulated pulpal pressure (SPP): submitted to $20 \mathrm{~cm} \mathrm{H}_{2} \mathrm{O}$ of simulated pulpal pressure (Fig. 1C) immersed in $\mathrm{H}_{2} \mathrm{O}$ for 6 months $\left(37^{\circ} \mathrm{C}\right)$ and finally sectioned into sticks (Feitosa et al., 2012a);

Resin-bonded teeth were sectioned in small resin-dentin sticks $(0.9 \times 0.9 \mathrm{~mm})$ suitable for the $\mu$ TBS. The sticks from the most peripheral zone presenting residual enamel were excluded. The exact cross-sectional area of each tested stick was measured with a digital calliper. The sticks were glued to a jig with a cyanoacrylate gel (Super Bonder gel; Loctite Henkel, Rocky Hill, CT, USA) and tested in universal testing machine (DL 2000, EMIC, São José dos Pinhais, Brazil) with a $500-\mathrm{N}$ load cell and $0.5 \mathrm{~mm} / \mathrm{min}$ cross-head speed. The $\mu$ TBS results were calculated and expressed in MPa. The value (MPa) attained from the sticks of the same resin-bonded tooth were averaged and the mean bond strength was used as one unit for statistical analysis. Ten resinbonded teeth $(\mathrm{n}=10)$ were evaluated for each condition. Subsequent to the $\mu$ TBS testing, the mode of failure of each single fractured stick was determined using a stereomicroscope at x100 (Olympus Sz 40-50; Tokyo, Japan). The fractures were classified as adhesive, mixed, cohesive in composite or cohesive in dentine. The $\mu$ TBS data were statistically analyzed using two-way ANOVA (adhesive and aging period) and Tukey's test at $\alpha=5 \%$.

\subsection{Nanoleakage evaluation}

Two central sticks were selected from each teeth of each subgroup $(n=10)$ and processed for nanoleakage assessment as previously described (Feitosa et al., 2012b). In brief, bonded sticks were immersed in $50 \mathrm{wt} \%$ ammoniacal silver nitrate $\left[\mathrm{Ag}\left(\mathrm{NH}_{3}\right)_{2}\right] \mathrm{NO}_{3}$ (aq) solution in total darkness for $24 \mathrm{~h}$. Subsequently, the specimens were rinsed in $\mathrm{H}_{2} \mathrm{O}$ to remove the excess silver nitrate and then immersed in a photo-developing solution for $8 \mathrm{~h}$ under fluorescent light $(60 \mathrm{~cm}$ from the specimens) to reduce silver ions into metallic silver grains along the resin-dentin interface. The silver-impregnated sticks were embedded in epoxy resin and wet-polished using \#600, \#1200, \#2000 SiC papers and diamond pastes (Buehler) 3, 1, and $0.25 \mu \mathrm{m}$. The specimens were ultrasonically cleaned for $20 \mathrm{~min}$ after each abrasive/polishing step. Finally, they were air-dried, dehydrated for $48 \mathrm{~h}$, coated with carbon and observed using a SEM (Inspect 50; FEI, Amsterdam, Netherlands) in backscattered electron mode for proper evaluation of silver impregnation along the interfaces.

\section{Results}

The water sorption of SEA-HEMA $\left(332.6 \pm 99.6 \mu \mathrm{g} / \mathrm{mm}^{3}\right)$ and SEA-GDMA $\left(369.1 \pm 99.5 \mu \mathrm{g} / \mathrm{mm}^{3}\right)$ were not different $(\mathrm{p}=0.848)$ and statistically higher than that of ERA-GDMA (150.2 $\pm 47.6 \mu \mathrm{g} /$ $\left.\mathrm{mm}^{3}\right)$. Similarly, the solubility of ERA-GDMA $\left(8.9 \pm 14.5 \mu \mathrm{g} / \mathrm{mm}^{3}\right)$ was significantly lower than that of SEA-HEMA $(99.0 \pm 67.6 \mu \mathrm{g}$ / $\mathrm{mm}^{3}$ ). No further significant differences were found in this experiment. The spreading of results of water sorption and solubility is found in Fig. 2A. Outcomes of flexural test are presented in Fig. 2B. Higher elastic moduli were found for ERA-GDMA (22.4 $\pm 8 \mathrm{MPa})$ and SEAGDMA (17.1 $\pm 14.4 \mathrm{MPa})$, which were statistically higher than SEAHEMA $(0.41 \pm 0.1 \mathrm{MPa})$, but similar between them $(\mathrm{p}=0.80)$. ERAHEMA achieved intermediate results. The degree of conversion of ERAGDMA $(86.2 \pm 6.4 \%)$ and SEA-GDMA $(84.2 \pm 3.7 \%)$ were significantly similar $(\mathrm{p}=0.984)$ and statistically higher (Fig. 3) than ERAHEMA $(66.4 \pm 10.3 \%)$. Again, ERA-HEMA obtained intermediary results.

Higher initial bond strength was attained with ERA-GDMA $(29.2 \pm 15.8 \mathrm{MPa})$ which was statistically higher than SEA-GDMA and ERA-HEMA (Fig. 4). However, after 6-month simulated pulpal pressure, all experimental bonding agents dropped significantly $(\mathrm{p}<0.05)$ the bond strength, except SEA-GDMA ( $p=0.744)$. The fracture mode of sticks was predominantly adhesive for all groups. Fig. 5 depicts the nanoleakage of resin-dentin specimens after aging. Specimens created using ERA-GDMA (Fig. 5A) and SEA-GDMA (Fig. 5B) provided low silver infiltration and overall tight interface. Conversely, ERA-HEMA (Fig. 5C) and SEA-HEMA (Fig. 5D) depicted intense presence of gaps and silver nanoleakage.

\section{Discussion}

Both study hypothesis needs to be rejected, once GDMA improved physicochemical properties as well as dentin bonding stability of self- 

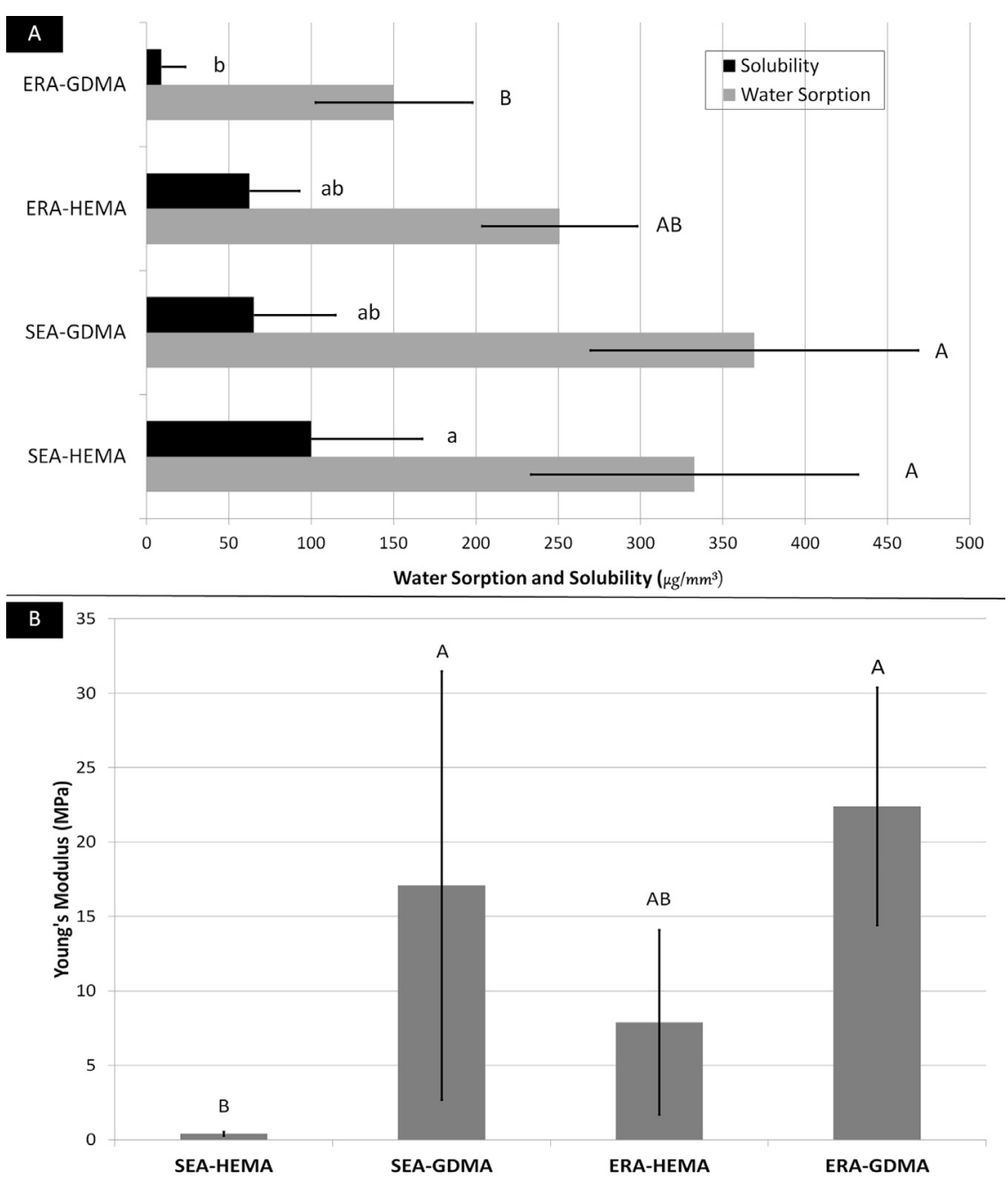

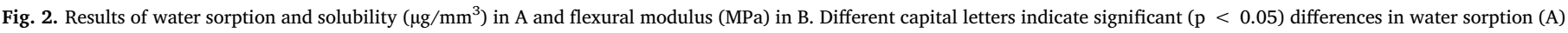
and flexural modulus (B). Different small case letters depict statistical differences $(\mathrm{p}<0.05)$ in solubility.

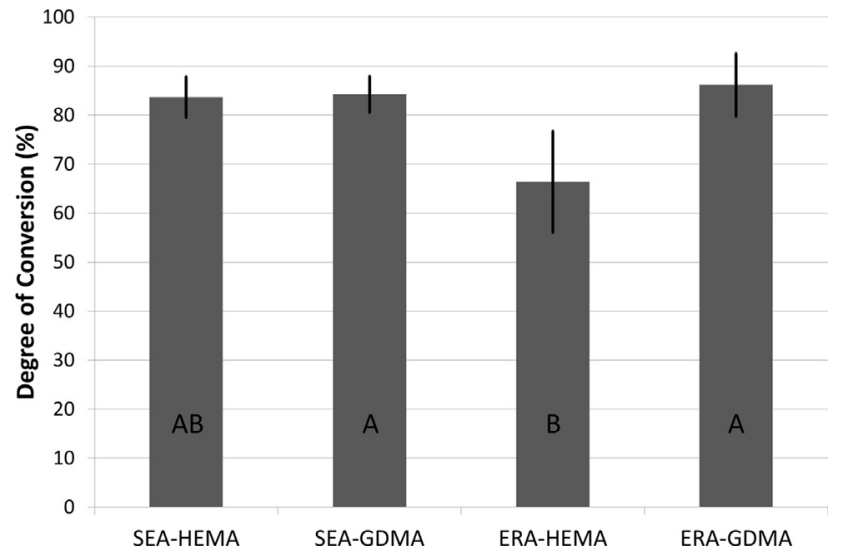

Fig. 3. Degree of conversion outcomes (\%). Different letters represent significant difference between groups $(\mathrm{p}<0.05)$.

etch strategy. Herein, four experimental simplified adhesives were employed, two etch-and-rinse and two self-etch, with equal composition apart from the presence of HEMA or GDMA in same concentrations. All further components, acidic functional monomer, hydrophobic dimethacrylates and initiators (Van Landuyt et al., 2007), were included in standardized concentration in order to assess solely the influence of GDMA in comparison to HEMA on the selected physicochemical properties and bonding ability to dentin.

HEMA is a relatively hydrophilic monomer frequently added to dental adhesives (Van Dijken, 2013), as it works ensuring optimal wetting of dentin surface and contributing as a solvent (Barbosa et al., 2014). Therefore, it improves the stability of adhesive solution containing hydrophobic and hydrophilic compounds (Van Landuyt et al., 2007), especially in the presence of water (Rodrigues et al., 2015). Furthermore, HEMA facilitates the infiltration of adhesive resin around partially demineralized collagen fibrils (Van Landuyt et al., 2008). Major drawback of such monomer is that, upon polymerization, only linear polymer chains are constructed because it is a mono-methacrylate, and its hydrophilic nature increases the water uptake. Altogether, these properties increase the degradation of adhesive interface (Van Landuyt et al., 2008; Rodrigues et al., 2015).

The proposal of the present investigation was to study the performance of simplified dental adhesives without the presence of HEMA, but rather containing another hydrophilic monomer with similar chemical characteristics. GDMA (MW $228.24 \mathrm{~g} / \mathrm{mol}$ ) was the monomer of choice because it is a low molecular weight hydrophilic monomer like HEMA (MW $113.14 \mathrm{~g} / \mathrm{mol}$ ), but possesses two methacrylate functionalities along with one hydroxyl unit (Fig. 1A). Overall, present outcomes have demonstrated several improvements of GDMA on physicochemical properties. Higher water sorption and solubility were attained with self-etch adhesives. A suitable explanation for this is the presence of hydrophilic acidic functional monomer in composition, which increases the hydrophilicity of these adhesives (Ito et al., 2010). 


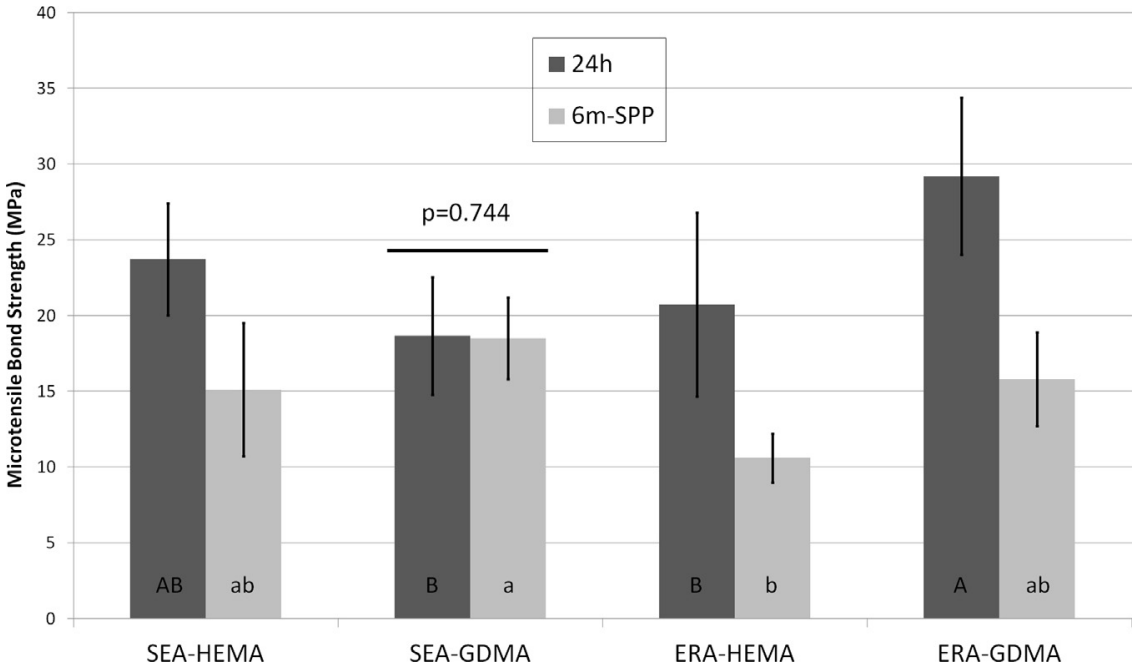

Fig. 4. Results of microtensile bond strength test (MPa). Different capital letters indicate significant $(\mathrm{p}<0.05)$ differences among immediate groups whilst different small case letters depict statistical differences $(\mathrm{p}<0.05)$ among groups submitted to aging under simulated pulpal pressure for 6 months. The horizontal bar represents statistical similarity between before and after aging within the same adhesive ( $\mathrm{p}>0.05)$.
The use of GDMA in the model etch-and-rinse adhesive achieved lowest water sorption and solubility, likely thanks to the additional polymer crosslinks provided by the dimethacrylate nature of GDMA, which might create stable polymer mesh with reduced hydrolysis likelihood (Dailing et al., 2014).

Further evidence demonstrating the crosslinking ability of GDMA in adhesive resins was the outcome of three-point bending test. Both experimental adhesives containing GDMA obtained high elastic modulus (Fig. 2B), with statistical significance difference for the self-etch ones. Indeed, SEA-HEMA tends to form linear polymeric chains, with few crosslinks, reducing the rigidity and elastic modulus of final resin (Van Landuyt et al., 2007). Moreover, the presence of two methacrylate functionalities in GDMA ameliorated the degree of conversion of etchand-rinse adhesive. Moreover, GDMA might undergo cyclization due to the formation of primary cycles by the pendant vinylic double bonds. More methacrylate groups yield in higher double bonds to be broken and transformed in free radicals, thus, more monomers are prone to be included in the chain reaction. Further important issue to be considered is the longer spacer chain of GDMA in comparison to HEMA. This has been demonstrated to improve the mobility of monomers during

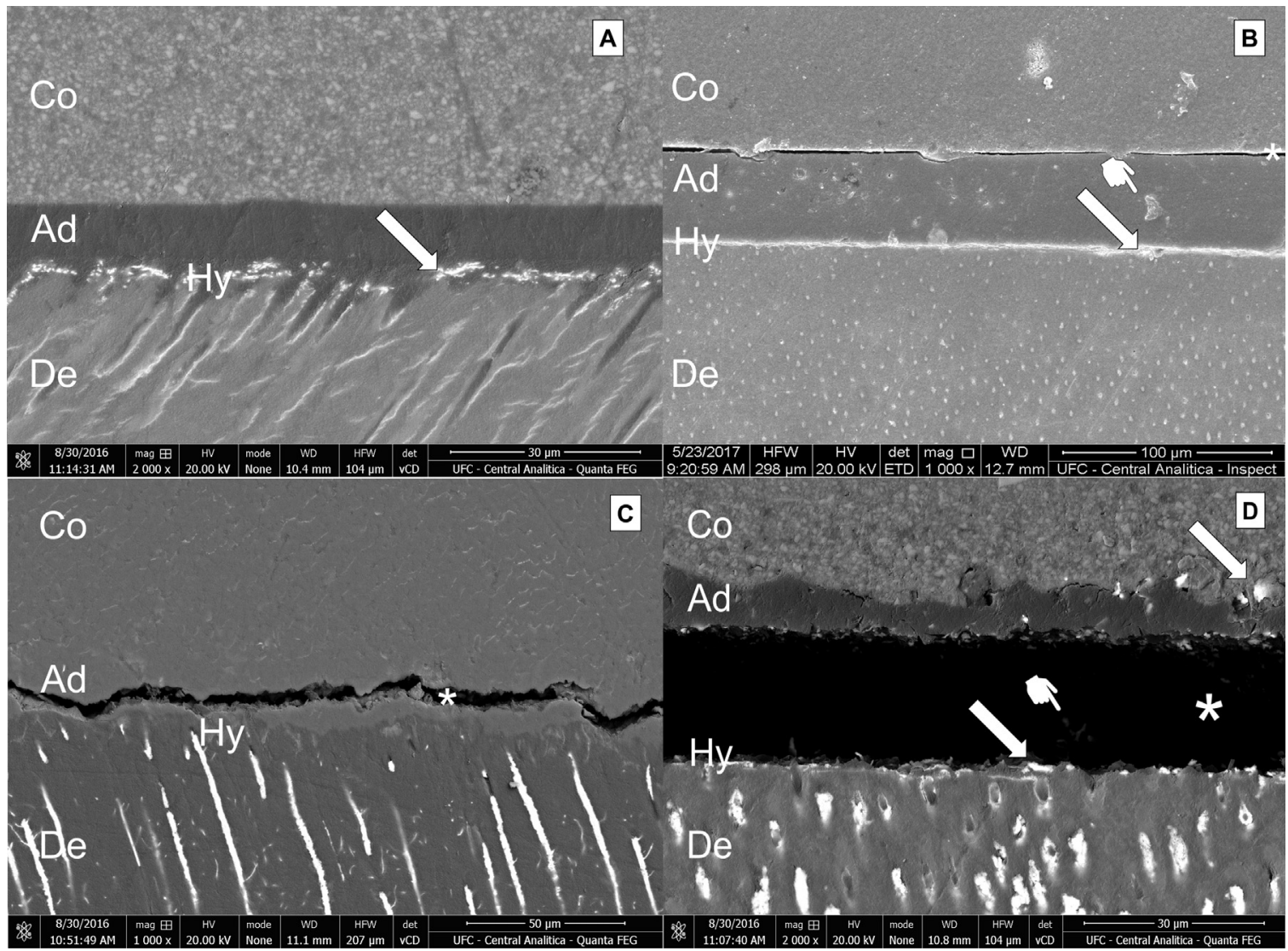

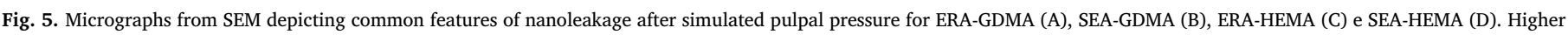

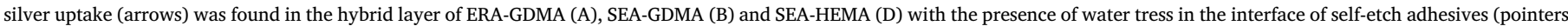

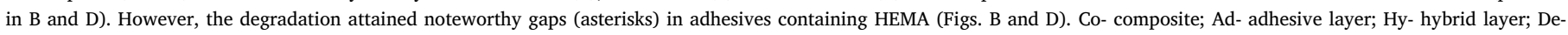
dentin. 
polymerization without altering the final degree of conversion (Gajewski et al., 2012). Therefore, one may speculate that for self-etch adhesives, the lack of statistical difference between HEMA and GDMA does not mean necessarily that both polymers possess similar degree of crosslinking (Coessens et al., 2001).

Apart from the physicochemical properties, a strikingly important feature for dental adhesives is the initial bond strength achieved, and more relevant is the stability of the bond strength after aging. All present bond strength values were in an acceptable (higher than $5 \mathrm{MPa}$ according to ISO 11405:2015) range to induce adequate bonding for resin composite restorations. An important outcome to highlight concerning the $\mu$ TBS test is the higher initial bond strength of ERA-GDMA than ERA-HEMA. These results may likely be related to optimal wetting ability of GDMA, adequate penetration in demineralized collagen mesh and improved polymerization crosslinking, the latter is difficult to attain in water-wet environment (Dailing et al., 2014).

Some investigations (Takahashi et al., 2013; Chiba et al., 2016) showed that HEMA and TEGDMA (MW $286.0 \mathrm{~g} / \mathrm{mol}$ ) are able to penetrate in spaces around collagen fibrils due to their small chemical structure. Therefore, GDMA might also have an optimal infiltration capacity, once its molecular weight is lower than that of TEGDMA. Besides, the presence of GDMA in the self-etch adhesive has engaged dentin bonding stability for this system. With etch-and-rinse adhesives, reduction on bond strength was already expected (Tjäderhane et al., 2013; Tezvergil-Mutluay et al., 2015) due to the rapid collagen degradation and water seepage in hybrid layer (Fig. 5A). As SEAs expose less collagen fibrils than ERAs (Tezvergil-Mutluay et al., 2015; Sarr et al., 2010), the former tend to resist more to degradation than the latter (Tezvergil-Mutluay et al., 2015).

In the present study, only SEA containing GDMA maintained the bond strength after 6 months of simulated pulpal pressure. This highlights the protection of hybrid layer provided by GDMA, confirmed by the low silver uptake in Fig. 5B. It is hypothesized that bond strength reduction of HEMA-containing SEA after 6 months might be related to the highly hydrophilic characteristic of HEMA and HEMA-phosphate (acidic functional monomer), both creating linear polymers which are more prone to degradation (Zanchi et al., 2013) and water uptake. Indeed, this explains the formation of water channels (water trees) in hybrid layer (Fig. 5D) (Ito et al., 2010). Yet, the presence of HEMA negatively interferes on the adhesion-decalcification process of self-etch adhesives (Yoshida et al., 2012), reducing the formation of ionic interactions with hydroxyapatite and increasing the nanoleakage (Yoshida et al., 2012). Nevertheless, the mechanism of nanolayering reinforcement of resin-dentin bond durability was recently questioned (Tian et al., 2016) which may turn such hypothesis uncertain.

Particularly for self-etch adhesive containing HEMA, the high degree of conversion did not result in high stiffness as demonstrated in Young's modulus assessment. This indicates the formation of linear polymers which are more likely to plasticization, water seepage and degradation, as evidenced in microtensile bond strength outcomes (Fig. 4).

In a recent investigation, Mahdan et al. (2013) concluded that commercial HEMA-free adhesives attained bond strength reduction after simulated pulpal pressure, but none of the tested adhesives had GDMA in composition as a substitute for HEMA. Some studies (Zanchi et al., 2013, 2011) already showed satisfactory bond strength outcomes replacing HEMA by surfactant dimethacrylate monomers, such as PEG 400 UDMA. However, none of these surfactant monomers are too small to properly infiltrate the intrafibrillar spaces of collagen in hybrid layer (Chiba et al., 2016). Conversely, GDMA formed tight interface in both adhesive strategies (Fig. 5), providing adequate polymerization (Fig. 3) and bonding resistance to aging.

\section{Conclusion}

In conclusion, within the limitations of this investigation, GDMA has the potential to replace HEMA as a diluent monomer in etch-and-rinse and self-etch simplified adhesives. With GDMA, better physicochemical properties are attained and stability of dentin bond is accomplished for self-etch adhesive.

\section{Acknowledgments}

This research was supported by Brazilian grants from CNPq (grant 457931/2014-0, PI VPF) and CAPES (AUXPE 23038.006958/2014-96, PI VPF). The authors have no financial or commercial conflicts of interest in any of the materials used in this investigation.

\section{References}

Argolo, S., Mathias, P., Aguiar, T., Lima, A., Santos, S., Foxton, R., Cavalcanti, A., 2015. Effect of agitation and storage temperature on water sorption and solubility of adhesive systems. Dent. Mater. J. 34, 1-6.

Barbosa, M.O., de Carvalho, R.V., Demarco, F.F., Ogliari, F.A., Zanchi, C.H., Piva, E., da Silva, A.F., 2015. Experimental self-etching HEMA-free adhesive systems: cytotoxicity and degree of conversion. J. Mater. Sci. Mater. Med. 26, 5370.

Becher, R., Kopperud, H.M., Al, R.H., Samuelsen, J.T., Morisbak, E., Dahlman, H.J., Lilleaas, E.M., Dahl, J.E., 2006. Pattern of cell death after in vitro exposure to GDMA, TEGDMA, HEMA and two compomer extracts. Dent. Mater. 22, 630-640.

Chiba, A., Zhou, J., Nakajima, M., Tan, J., Tagami, J., Scheffel, D.L., Hebling, J., Agee, K.A., Breschi, L., Grégoire, G., Jang, S.S., Tay, F.R., Pashley, D.H., 2016. The effects of ethanol on the size-exclusion characteristics of type I dentin collagen to adhesive resin monomers. Acta Biomater. 33, 235-241.

Chimeli, T.B., D'Alpino, P.H., Pereira, P.N., Hilgert, L.A., Di Hipólito, V., Garcia, F.C., 2014. Effects of solvent evaporation on water sorption/solubility and nanoleakage of adhesive systems. J. Appl. Oral. Sci. 22, 294-301.

Coessens, V., Pintauer, T., Matyjaszewski, 2001. Functional polymers by atom transfer radical polymerization. Prog. Polym. Sci. 26, 337-377.

Dailing, E.A., Lewis, S.H., Barros, M.D., Stansbury, J.W., 2014. Construction of monomerfree, highly crosslinked, water-compatible polymers. J. Dent. Res. 93, 1326-1331.

Feitosa, V.P., Correr, A.B., Correr-Sobrinho, L., Sinhoreti, M.A., 2012a. Effect of a new method to simulate pulpal pressure on bond strength and nanoleakage of dental adhesives to dentin. J. Adhes. Dent. 14, 517-524.

Feitosa, V.P., Leme, A.A., Sauro, S., Correr-Sobrinho, L., Watson, T.F., Sinhoreti, M.A. Correr, A.B., 2012b. Hydrolytic degradation of the resin-dentine interface induced by the simulated pulpal pressure, direct and indirect water ageing. J. Dent. 40, 1134-1143.

Gajewski, V.E., Pfeifer, C.S., Fróes-Salgado, N.R., Boaro, L.C., Braga, R.R., 2012. Monomers used in resin composites: degree of conversion, mechanical properties and water sorption/solubility. Braz. Dent. J. 23, 508-514.

Gallorini, M., Cataldi, A., di Giacomo, V., 2014. HEMA-induced cytotoxicity: oxidative stress, genotoxicity and apoptosis. Int Endod. J. 47, 813-818.

ISO 4049, 2009. Dentistry-resin based filling materials. Int. Organ. Stand. 1-27.

Ito, S., Hoshino, T., Iijima, M., Tsukamoto, N., Pashley, D.H., Saito, T., 2010. Water sorption/solubility of self-etching dentin bonding agents. Dent. Mater. 26, 617-626.

Loguercio, A.D., Loeblein, F., Cherobin, T., Ogliari, F., Piva, E., Reis, A., 2009. Effect of solvent removal on adhesive properties of simplified etch-and-rinse systems and on bond strengths to dry and wet dentin. J. Adhes. Dent. 11, 213-219.

Mahdan, M.H., Nakajima, M., Foxton, R.M., Tagami, J., 2013. Combined effect of smear layer characteristics and hydrostatic pulpal pressure on dentine bond strength of HEMA-free and HEMA-containing adhesives. J. Dent. 41, 861-871.

Miletic, V., Santini, A., 2012. Micro-Raman spectroscopic analysis of the degree of conversion of composite resins containing different initiators cured by polywave or monowave LED units. J. Dent. 40, 106-113.

Münchow, E.A., Zanchi, C.H., Ogliari, F.A., Silva, M.G., de Oliveira, I.R., Piva, E., 2014 Replacing HEMA with alternative dimethacrylates in dental adhesive systems: evaluation of polymerization kinetics and physicochemical properties. J. Adhes. Dent. 16, 221-228.

Rodrigues, S.B., Collares, F.M., Leitune, V.C., Schneider, L.F., Ogliari, F.A., Petzhold, C.L., Samuel, S.M., 2015. Influence of hydroxyethyl acrylamide addition to dental adhesive resin. Dent. Mater. 31, 1579-1586.

Sarr, M., Kane, A.W., Vreven, J., Mine, A., Van Landuyt, K.L., Peumans, M., Lambrechts, P., Van Meerbeek, B., De Munck, J., 2010. Microtensile bond strength and interfacial characterization of 11 contemporary adhesives bonded to bur-cut dentin. Oper. Dent. 35, 94-104.

Takahashi, M., Nakajima, M., Tagami, J., Scheffel, D.L., Carvalho, R.M., Mazzoni, A, Cadenaro, M., Tezvergil-Mutluay, A., Breschi, L., Tjäderhane, L., Jang, S.S., Tay, F.R., Agee, K.A., Pashley, D.H., 2013. The importance of size-exclusion characteristics of type I collagen in bonding to dentin matrices. Acta Biomater. 9, 9522-9528.

Tezvergil-Mutluay, A., Pashley, D., Mutluay, M.M., 2015. Long-term durability of dental adhesives. Curr. Oral. Health Rep. 2, 174-181.

Tian, F.C., Wang, X.Y., Huang, Q., Niu, L.N., Mitchell, J., Zhang, Z.Y., Prananik, C., Zhang, L., Chen, J.H., Breschi, L., Pashley, D.H., Tay, F.R., 2016. Effect of nanolayering of calcium salts of phosphoric acid ester monomers on the durability of resindentin bonds. Acta Biomater. 38, 190-200.

Tjäderhane, L., Nascimento, F.D., Breschi, L., Mazzoni, A., Tersariol, I.L.C., Geraldeli, S., Tezvergil-Mutluay, A., Carrilho, M., Carvalho, R.M., Tay, F.R., Pashley, D.H., 2013. 
Strategies to prevent hydrolytic degradation of the hybrid layer-A review. Dent. Mater. 29, 999-1011.

Van Dijken, J.W., 2013. A 6-year prospective evaluation of a one-step HEMA-free selfetching adhesive in Class II restorations. Dent. Mater. 29, 1116-1122.

Van Landuyt, K.L., Snauwaert, J., De Munck, J., Peumans, M., Yoshida, Y., Poitevin, A., Coutinho, E., Suzuki, K., Lambrechts, P., Van Meerbeek, B., 2007. Systematic review of the chemical composition of contemporary dental adhesives. Biomaterials 28, 3757-3785.

Van Landuyt, K.L., Snauwaert, J., Peumans, M., De Munck, J., Lambrechts, P., Van Meerbeek, B., 2008. The role of HEMA in one-step self-etch adhesives. Dent. Mater. 24, 1412-1419.

Van Meerbeek, B., Yoshihara, K., Yoshida, Y., Mine, A., De Munck, J., Van Landuyt, K.L.,
2011. State of the art of self-etch adhesives. Dent. Mater. 27, 17-28.

Yoshida, Y., Yoshihara, K., Hayakawa, S., Nagaoka, N., Okihara, T., Matsumoto, T.,

Minagi, S., Osaka, A., Van Landuyt, K., Van Meerbeek, B., 2012. HEMA inhibits interfacial nano-layering of the functional monomer MDP. J. Dent. Res. 91, 1060-1065. Zanchi, C.H., Münchow, E.A., Ogliari, F.A., de Carvalho, R.V., Chersoni, S., Prati, C.,

Demarco, F.F., Piva, E., 2013. Effects of long-term water storage on the microtensile bond strength of five experimental self-etching adhesives based on surfactants rather than HEMA. Clin. Oral. Investig. 17, 833-839.

Zanchi, C.H., Münchow, E.A., Ogliari, F.A., de Carvalho, R.V., Chersoni, S., Prati, C., Demarco, F.F., Piva, E., 2011. A new approach in self-etching adhesive formulations: replacing HEMA for surfactant dimethacrylate monomers. J. Biomed. Mater. Res B Appl. Biomater. 99, 51-57. 